\title{
Effects of a high walnut and high cashew nut diet on selected markers of the metabolic syndrome: a controlled feeding trial
}

\author{
Janine Mukuddem-Petersen ${ }^{1,2}$, Welma Stonehouse (Oosthuizen) ${ }^{1,3}$, Johann C. Jerling ${ }^{1}$, \\ Susanna M. Hanekom ${ }^{1}$ and Zelda White ${ }^{1}$ \\ ${ }^{1}$ School of Physiology, Nutrition and Consumer Science, North-West University (Potchefstroom Campus), Potchefstroom, \\ South Africa \\ ${ }^{2}$ School of Computer, Mathematical and Statistical Sciences, North-West University (Potchefstroom Campus), Potchefstroom, \\ South Africa \\ ${ }^{3}$ Institute of Food, Nutrition and Human Health, Massey University (Albany Campus), North Shore, Auckland, New Zealand
}

(Received 18 July 2006 - Revised 20 December 2006 - Accepted 3 January 2007)

\begin{abstract}
We investigated the effects of a high walnut diet and a high unsalted cashew nut diet on selected markers of the metabolic syndrome. In a randomized, parallel, controlled study design, sixty-four subjects having the metabolic syndrome (twenty-nine men, thirty-five women) with a mean age of 45 (SD 10) years and who met the selection criteria were all fed a 3-week run-in control diet. Hereafter, participants were grouped according to gender and age and then randomized into three groups receiving a controlled feeding diet including walnuts, or unsalted cashew nuts or no nuts for 8 weeks. Subjects were required to have lunch at the metabolic ward of the Nutrition Department of the North-West University (Potchefstroom Campus). Both the walnut and the unsalted cashew nut intervention diets had no significant effect on the HDL-cholesterol, TAG, total cholesterol, LDL-cholesterol, serum fructosamine, serum high-sensitivity C-reactive protein, blood pressure and serum uric acid concentrations when compared to the control diet. Low baseline LDL-cholesterol concentrations in the cashew nut group may have masked a possible nut-related benefit. Plasma glucose concentrations increased significantly $(P=0.04)$ in the cashew nut group compared to the control group. By contrast, serum fructosamine was unchanged in the cashew nut group while the control group had significantly increased $(P=0 \cdot 04)$ concentrations of this short-term marker of glycaemic control. Subjects displayed no improvement in the markers of the metabolic syndrome after following a walnut diet or a cashew nut diet compared to a control diet while maintaining body weight.
\end{abstract}

Metabolic syndrome: Hyperlipidaemia: Hypertension: Obesity: Lipids: Fatty acids: Diet

The National Cholesterol Education Program's Adult Treatment Panel III (ATP III) defines the metabolic syndrome by easily measured clinical parameters that include: increased abdominal circumference, elevated TAG, low HDL-cholesterol (HDL-C), elevated fasting blood glucose and/or elevated blood pressure (BP). Three of these five are required for diagnosis (National Cholesterol Education Program, 2001).

From the third National Health and Nutrition Examination Survey (NHANES III) (Ford, 2004) and the THUSA study (THUSA is the acrynom for Transition and Health during Urbanisation in South Africa, and is also the Tswana word for "help") (Oosthuizen et al. 2002) it is evident that the increasing prevalence of the metabolic syndrome is a health problem not only for developed countries but also for developing countries.

This syndrome has been identified as a target for dietary therapies (Wirfalt et al. 2001) to reduce the risk of CVD (Shirai, 2004) and type 2 diabetes (Jimenez-Cruz et al.
2003). In lieu of the therapeutics of the metabolic syndrome various researchers have investigated different dietary approaches. Some of the recent dietary interventions range from caloric restriction (Wien et al. 2003; Muzio et al. 2005), type of diet, e.g. Mediterranean (Esposito et al. 2004; Michalsen et al. 2006), type and/or amount of dietary fat (Riccardi et al. 2004; Freire et al. 2005), amount of carbohydrates (Dansinger \& Schaefer, 2006), increasing the intake of certain minerals (He et al. 2006) and increasing dietary intake of certain functional foods (e.g. nuts, grapefruit) (Pieters et al. 2005; Fujioka et al. 2006).

Riccardi et al. (2004) concluded that the diet for the treatment of the metabolic syndrome should be limited in the intake of saturated fat, while high-fibre/low-glycaemic index foods should be used without specific limitations (Giacco et al. 2000). Recently, in the Framingham Offspring cohort, the researchers found glycaemic index and glycaemic load (a measure of both carbohydrate quality and quantity) were

Abbreviations: ATP III, National Cholesterol Education Program's Adult Treatment Panel III; BP, blood pressure; \%E, percentage of total energy; HDL-C, HDL-cholesterol; LDL-C, LDL-cholesterol; S-hs CRP, serum high-sensitivity C-reactive protein; TC, total cholesterol.

* Corresponding author: Dr Janine Mukuddem-Petersen, School of Computer, Mathematical and Statistical Sciences, North-West University (Potchefstroom Campus), Private Bag X 6001, Potchefstroom, South Africa, fax +27 18299 2570, email Janine.MukuddemPetersen@NWU.ac.za 
positively associated with the prevalence of the metabolic syndrome (McKeown et al. 2004).

Epidemiological findings indicate that frequent nut consumption offers protection from fatal and non-fatal CHD events (Sabate, 1993). Nuts have a low glycaemic index (Foster-Powell et al. 2002) and are a rich source of protein, unsaturated fatty acids (MUFA and PUFA), vitamin E, $B_{6}$, folic acid and niacin, fibre, magnesium, potassium, arginine, phytosterols and other phytochemical compounds (such as polyphenols and ellagic acid) (Dreher et al. 1996). The protective effects of nuts are mediated through several mechanisms. Specifically, the health benefits of walnuts include lowering cholesterol, increasing the ratio of HDL-C to total cholesterol (TC), decreasing TAG and increasing HDL-C, reducing inflammation and improving arterial function in patients with type 2 diabetes and hyperlipidaemia (Ros et al. 2004; Tapsell et al. 2004; Zhao et al. 2004; Zibaeenezhad et al. 2005). Besides our recent contribution (Pieters et al. 2005), there is a scarcity of literature on the effects of cashew nut interventions.

In fact, to date there are no other studies that investigated the effects of nuts on either markers of the metabolic syndrome or using subjects with metabolic syndrome. Therefore, the primary objective of the present study was to determine the effects of a high walnut diet and a high unsalted cashew nut diet on markers of this syndrome compared to a control diet. In this contribution we report the effects on the following markers: serum lipids (TC, LDL-cholesterol (LDL-C), HDL-C and TAG), serum fructosamine, plasma glucose, BP, serum uric acid and serum high-sensitivity $\mathrm{C}$-reactive protein (S-hs CRP).

\section{Subjects and methods}

\section{Subjects}

All participants gave written informed consent and the study was approved by the Ethics Committee of the Potchefstroom Campus of the North-West University. Sixty-eight White/Caucasian volunteers with the metabolic syndrome were recruited mainly from the Potchefstroom Campus of the North-West University and surrounding areas in Potchefstroom, South Africa. According to the power calculations providing $80 \%$ power at $5 \%$ significance based on LDL-C data from several studies (Chisholm et al. 1998; Jenkins et al. 2002; Lovejoy et al. 2002; Sabate et al. 2003; Ros et al. 2004), twenty subjects per treatment group were needed to detect a decrease of $15 \%(0.6 \mathrm{mmol} / \mathrm{l})$ which might reduce the risk of CVD by more than $20 \%$ (Moruisi et al. 2006). The ATP III criteria for the diagnosis of the metabolic syndrome was used. In this regard, the metabolic syndrome was defined as the presence of three or more of the following criteria (Ford et al. 2002): abdominal obesity (waist circumference $>88 \mathrm{~cm}$ for women or $>102 \mathrm{~cm}$ for men); fasting $\mathrm{TAG} \geq 1.7 \mathrm{mmol} / \mathrm{l}$; HDL-C $\leq 1.0 \mathrm{mmol} / \mathrm{l}$ for men, HDL-C $\leq 1.3 \mathrm{mmol} / \mathrm{l}$ for women; $\mathrm{BP} \geq 130 / 85 \mathrm{mmHg}$ (the use of anti-hypertensive medication was also an indication of high BP) and fasting glucose $\geq 6.1 \mathrm{mmol} / 1$ (fasting finger prick blood glucose concentrations were measured with a SureStep ${ }^{\mathrm{TM}}$ blood glucose meter (Lifescan Inc., Milpitas, CA, USA), using Fine Point lancets, and SureStep ${ }^{\mathrm{TM}}$ test strips (code 11).

Additional inclusion criteria included subjects being able to comply with controlled feeding conditions; being willing and able to eat walnuts and cashew nuts, and participants had to be older than 21 and younger than 65 years. Pregnancy or lactation, thiazide $\left(>25 \mathrm{mg} / \mathrm{d}\right.$ ) and $\beta$-blocker (non-specific, $\beta_{1}$ and $\beta_{2}$ use, subjects having nut allergies and diagnosed diabetes formed part of the exclusion criteria.

\section{Study design}

A randomized, controlled, parallel, study design was used. The study protocol consisted of a 3 -week run-in period during which the subjects consumed a control diet (percentage of total energy (\%) intake from protein-carbohydratefat $=20: 47: 33$; Table 1). After the run-in period participants were grouped according to gender and age and then into three groups by randomly drawing numbers from a hat. Group one received walnuts ( $n$ 21), group two received unsalted cashew nuts ( $n$ 21), while group three continued with the control diet without any nuts or nut-based ingredients ( $n$ 22). Furthermore, these three intervention diets were followed for 8 weeks. Due to practical reasons the study was divided into three cohorts distributed over a 1-year period. All the food was provided to the participants for the duration

Table 1. Planned and analysed composition of diets as well as the habitual diets

\begin{tabular}{|c|c|c|c|c|c|c|c|}
\hline \multirow{2}{*}{$\begin{array}{l}\text { Nutrients, glycaemic index and } \\
\text { glycaemic load }\end{array}$} & \multirow{2}{*}{$\begin{array}{c}\text { Habitual diet prior to dietary } \\
\text { intervention }(n 64) \\
\text { FFQ† }\end{array}$} & \multicolumn{2}{|c|}{ Walnut diet (n 21) } & \multicolumn{2}{|c|}{ Cashew nut diet ( $n 21)$} & \multicolumn{2}{|c|}{ Control diet ( $n 22)$} \\
\hline & & Planned† & Analysed $\ddagger$ & Planned† & Analysed $\ddagger$ & Planned $†$ & Analysed \\
\hline Protein (\% of energy) & $15 \cdot 1$ & $15 \cdot 7$ & $17 \cdot 5$ & $16 \cdot 2$ & $19 \cdot 1$ & $16 \cdot 4$ & $19 \cdot 6$ \\
\hline Carbohydrate (\% of energy) & $49 \cdot 2$ & $48 \cdot 9$ & $42 \cdot 1$ & $46 \cdot 8$ & $44 \cdot 4$ & $51 \cdot 3$ & $47 \cdot 2$ \\
\hline Fat (\% of energy) & $33 \cdot 2$ & $35 \cdot 0$ & $40 \cdot 3$ & $37 \cdot 1$ & $36 \cdot 5$ & $32 \cdot 8$ & $33 \cdot 2$ \\
\hline SFA (\% of energy) & $11 \cdot 0$ & $7 \cdot 49$ & $8 \cdot 2$ & $9 \cdot 25$ & $9 \cdot 4$ & $7 \cdot 7$ & $12 \cdot 2$ \\
\hline MUFA (\% of energy) & $11 \cdot 3$ & $10 \cdot 6$ & $10 \cdot 7$ & $15 \cdot 9$ & $16 \cdot 3$ & $9 \cdot 4$ & $11 \cdot 3$ \\
\hline PUFA ( $\%$ of energy) & $7 \cdot 5$ & $15 \cdot 1$ & $21 \cdot 4$ & $7 \cdot 83$ & $10 \cdot 8$ & $8 \cdot 1$ & 9.5 \\
\hline Cholesterol (mg/d) & 316 & 226 & - & 224 & - & 246 & - \\
\hline Fibre $(g / d)$ & $30 \cdot 7$ & $34 \cdot 1$ & - & 33.4 & - & $27 \cdot 8$ & - \\
\hline Glycaemic index§ & - & 54 & - & 53 & - & 56 & - \\
\hline Glycaemic load§ & - & 14 & - & 14 & - & 15 & - \\
\hline
\end{tabular}

† Determined by using the FoodFinder 2 Program (Medical Research Council of South Africa, Tygerberg; mean of $14 \mathrm{~d}$ menu).

‡Laboratory analysis.

$\S$ Calculated with the aid of the glycaemic index and glycaemic load tables of Foster-Powell et al. (2002). 
of the trial. Fasting blood samples, oral glucose tolerance tests, anthropometric measurements and BP measurements were taken before (after the 3-week run-in period) and after the intervention period (8-week controlled feeding). BMI $\left(\mathrm{kg} / \mathrm{m}^{2}\right)$ was calculated. In addition, the weighing of subjects was done twice weekly throughout the run-in period and the experimental phase. The subjects were informed of all aspects of the study before commencement.

\section{Diet}

The proportion of total energy (ranging from 63 to $108 \mathrm{~g} / \mathrm{d}$ ) from nuts was $20 \%$. Except for the nuts, the diets were identical. This was achieved by making proportional reductions to all food portions in the walnut and the unsalted cashew nut diet menus to accommodate the energy supplied by the respective nuts (Tables 1 and 2). The study featured a highly controlled feeding protocol. In this regard, all subjects were required to have their lunch at the metabolic ward of the Department of Nutrition at the Potchefstroom Campus of the North-West University. Breakfast and dinner were provided in take-away format. Using pre-packed food parcels and a variety of set menu options ensured compliance. On a daily basis $10 \%$ of the total energy intake was calculated in the form of 'additional points'. In this regard, a list of foods with their associated number of points was provided to the participants. In order to ensure total energy intake and some freedom of choice, participants were advised to choose any foods from the list, provided they added up to the allotted number of points for their respective energy intakes for that day. A validated FFQ and physical activity questionnaire, measuring activity index, were analysed in order to determine the correct energy intake requirements for the maintenance of body weight for each participant. The validated physical activity questionnaire is based on the Baecke physical activity questionnaire (Kruger et al. 2004). Evidence of underreporting was found when the ratio of energy intake to BMR was less than 1.2 (Bingham, 1991; Briefel et al. 1997). In the light of this fact, the subjects that underreported were interviewed again by the registered dietitian to obtain a more accurate report on their habitual energy intake.

A $14 \mathrm{~d}$ menu cycle was designed for five amounts of energy intake, ranging from 8000 to $14000 \mathrm{~kJ} / \mathrm{d}(1905-3333 \mathrm{kcal} / \mathrm{d})$. It was planned by using the FoodFinder 2 program (Medical Research Council of South Africa, Tygerberg), which is based on the South African food composition tables (Langenhoven et al. 1991). The macronutrient profiles and fatty acid distribution of the three diets were analysed chemically to validate the diet composition. Duplicate portions of breakfast, lunch and dinner for the $14 \mathrm{~d}$ menu cycle were collected daily, homogenized and pooled in a container and frozen at $-84^{\circ} \mathrm{C}$ until the analysis was done.

\section{Compliance to dietary intervention}

Quality control and compliance with the protocol were ensured among study participants by the following means: (1) foods were weighed to the nearest gram before being served to the participants; (2) the principal investigator, a registered dietitian, supervised mealtimes and ensured the complete intake of all study foods; (3) participants kept food diaries of the additional points used and possible left-overs were collected and weighed (by researchers). In addition, any deviation from the study protocol were recorded in these diaries (these diaries were reviewed by the investigators during the study); (4) participants were weighed twice weekly and the energy intake was adjusted (especially during the first 3 -week run-in period) in order to maintain body weight; and (5) participants were urged to maintain the same activity level throughout the study. Lastly, those individuals who used chronic medication (e.g. lipid-lowering medication) at baseline were instructed to continue use and to maintain the same dosage for the duration of the trial.

Table 2. Macronutrient composition of $100 \mathrm{~g}$ walnuts and unsalted cashew nuts

\begin{tabular}{|c|c|c|c|c|c|c|}
\hline \multirow[b]{3}{*}{ Selected nutrients } & \multicolumn{3}{|c|}{ Walnuts } & \multicolumn{3}{|c|}{ Cashew nuts } \\
\hline & \multicolumn{2}{|c|}{ Laboratory analysis } & \multirow{2}{*}{$\begin{array}{l}\text { Food composition } \\
\text { tables }+(\mathrm{g})\end{array}$} & \multicolumn{2}{|c|}{ Laboratory analysis } & \multirow{2}{*}{$\begin{array}{c}\text { Food composition } \\
\text { tablest }(\mathrm{g})\end{array}$} \\
\hline & $g$ & $\% \neq$ & & $g$ & $\% \ddagger$ & \\
\hline Energy (kJ) & & & 2686 & & & 2402 \\
\hline Energy (kcal) & & & 642 & & & 574 \\
\hline Protein & $13 \cdot 0$ & & $14 \cdot 3$ & $20 \cdot 5$ & & $15 \cdot 3$ \\
\hline Carbohydrate & 3.9 & & $13 \cdot 5$ & $19 \cdot 4$ & & $26 \cdot 6$ \\
\hline Fibre & $5 \cdot 75$ & & $6 \cdot 10$ & $5 \cdot 62$ & & $4 \cdot 80$ \\
\hline Total fat & $73 \cdot 2$ & & 61.9 & $48 \cdot 4$ & & $46 \cdot 4$ \\
\hline MUFA & $13 \cdot 4$ & $18 \cdot 3$ & $14 \cdot 2$ & $25 \cdot 6$ & 52.9 & $27 \cdot 3$ \\
\hline Oleic acid (C18:1) & $13 \cdot 2$ & $18 \cdot 0$ & 21.5 & $25 \cdot 5$ & $52 \cdot 6$ & $57 \cdot 8$ \\
\hline PUFA & $53 \cdot 8$ & 73.5 & $39 \cdot 1$ & $15 \cdot 3$ & 31.6 & $7 \cdot 84$ \\
\hline Linoleic acid (C18:2) & $44 \cdot 7$ & $61 \cdot 0$ & $51 \cdot 3$ & $15 \cdot 0$ & $31 \cdot 0$ & $16 \cdot 5$ \\
\hline$\alpha$-Linolenic acid (C18:3) & $9 \cdot 15$ & $12 \cdot 50$ & 11.00 & 0.25 & 0.51 & 0.34 \\
\hline SFA & $6 \cdot 00$ & $8 \cdot 20$ & 5.59 & $7 \cdot 51$ & $15 \cdot 5$ & $9 \cdot 16$ \\
\hline Palmitic acid (C16:0) & 4.41 & 6.02 & $6 \cdot 85$ & 4.08 & 8.43 & $9 \cdot 38$ \\
\hline Stearic acid (C18:0) & 1.47 & $2 \cdot 01$ & $1 \cdot 74$ & 3.09 & $6 \cdot 38$ & $6 \cdot 40$ \\
\hline
\end{tabular}

† Langenhoven et al. (1991); Kruger et al. (1992).

$\ddagger$ Percentage of total fatty acids. 


\section{Blood sampling and oral glucose tolerance test}

The subjects were required to fast overnight (12 h). A qualified nursing sister collected venous blood samples. For the preparation of serum, $20 \mathrm{ml}$ blood were drawn and left to clot. For determination of plasma glucose concentrations $5 \mathrm{ml}$ blood were collected in tubes containing potassium oxalate $(10 \mathrm{mg})$ and sodium fluoride $(12.5 \mathrm{mg})$.

After the fasting blood samples were collected, the oral glucose tolerance test was continued: $75 \mathrm{~g}$ glucose were dissolved in $300 \mathrm{ml}$ water; blood samples for the measurement of glucose were drawn again after $2 \mathrm{~h}$; blood was centrifuged for $15 \mathrm{~min}$ at $2000 \mathrm{~g}$ to yield serum; aliquots of serum were stored at $-82^{\circ} \mathrm{C}$ until the analysis was performed.

\section{Analytical methods}

The fatty acid composition of the nuts and diets was measured by GC as described by van Jaarsveld et al. (2000). The percentage protein was analysed by a general combustion method (AOAC Method 992.23; AOAC International, 2002) by using a LECO FP 528 (LECO Corporation, St Joseph, MI, USA), the percentage fat by a GAVIEZEL ${ }^{\circledR}$ method using the Büchi B 820 fat determination system with the Büchi B 815 extraction unit (Büchi Labortechnik AG, Flawil, Switzerland), the percentage fibre by the filter bag technique using the ANKOM 220 fibre analyser with F57 filter bags (ANKOM Technologies, Fairport, NY, USA), the percentage moisture with the air-oven (aluminium plate) method (AACC Method 44-161; American Association of Clinical Chemistry, 2003) and percentage ash with the AOAC Method 942.05 (AOAC International, 2002). The carbohydrate content was then calculated as the sum of the protein, fat, fibre, moisture and ash subtracted from 100 .

$\mathrm{CV}$ for all the laboratory analyses of blood samples were less than $5 \%$. Serum TC, HDL-C, TAG, uric acid and plasma glucose were measured on a Vitros DT60 II Chemistry System (Ortho-Clinical Diagnostics, Rochester, NY, USA) with Vitros reagents (catalogue numbers 153 2175, 133 5504, 1532159,1532134 and 1532316, respectively) and controls (catalogue numbers 842-0317 and 144-8042). Serum LDL-C was calculated using the Friedewald formula: (LDL$\mathrm{C}(\mathrm{mmol} / \mathrm{l})=\mathrm{TC}-\mathrm{TAG} / 2 \cdot 2-\mathrm{HDL}) . \quad$ S-hs $\quad \mathrm{CRP}$ was measured using the Synchron LX20 ${ }^{\circledR}$ clinical system (Beckman Coulter, Inc., Fullerton, CA, USA). Serum fructosamine was measured with a calorimetric method (catalogue number 1930010; Roche, Basel, Switzerland). BP measurements were obtained by taking a 7 min continuous measurement of cardiovascular parameters using the Finometer ${ }^{\mathrm{TM}}$ device (FMS; Finapres Measurement Systems, Arnhem, Netherlands).

\section{Statistical analyses}

The computer software package Statistica ${ }^{\circledR}$ (Statsoft Inc., Tulsa, OK, USA) was used for the analyses of the data. The statistical analysis was done in five steps. Initially, the variables were tested for normality using the Shapiro-Wilk's $W$ test. Non-normally distributed data were transformed into an approximately normal distribution by logarithmic and square-root transformations and again tested for normality.
Thereafter, descriptive statistics were done. Data that were normally distributed are expressed as mean and $95 \% \mathrm{CI}$. Data that are not normally distributed or logarithmic and square-root transformed are expressed as median (25, 75 percentiles). Furthermore, changes within groups, from baseline to end, were tested for significance by using the $t$ test for dependent samples in the case of parametric data and the Wilcoxon matched-pairs test in the case of non-parametric data. Also, differences in baseline and $\Delta$ (change from baseline to end) between the three groups were determined by using the ANOVA for parametric data and the Kruskal-Wallis ANOVA for non-parametric data. When significance between the changes in the three groups was indicated with the ANOVA, the Tukey honest significant difference test for unequal $N$ for parametric data was used to determine between which groups the differences occurred. Lastly, weightadjusted differences in baseline and $\Delta$ between the three groups were determined by using the analysis of covariance. Significance was set at $P \leq 0 \cdot 05$.

\section{Results \\ Subjects}

Four subjects discontinued the study for the following reasons: two had work obligations outside Potchefstroom, one had an unrelated medical condition and one went on a holiday during the study period. The remaining sixty-four subjects (twenty-nine men and thirty-five women, aged 45 (SD 10) years) all completed one of the three intervention diets. Compliance with the experimental diets was calculated as $90 \%$, taking into account the left-overs, food diaries and any deviation from the prescribed dietary protocols. Also, activity level was maintained throughout the study. In this regard, most of the participants had a sedentary lifestyle. The baseline characteristics of the subjects did not differ between groups (ANOVA; Table 3). Most of the subjects were obese (91\%) with high waist circumference values exceeding those indicated by the ATP III criteria. Of the subjects, $53 \%$ had high TAG concentrations, $42 \%$ had high systolic BP, $13 \%$ had high diastolic BP, $91 \%$ had low HDL-C and only $5 \%$ had high fasting glucose concentrations as indicated by the ATP III criteria. At baseline $13 \%$ of subjects had high hs-CRP concentrations, greater than $7.5 \mathrm{mg} / \mathrm{l}$ (as indicated by the producers of the diagnostic kit). Evidently, the subject characteristics at baseline were indicative of the metabolic syndrome. Also, of the entire study population only four were smokers (Table 3). Weight, BMI and waist circumference remained unchanged during the intervention period.

\section{Diet composition}

The participants' habitual energy intakes ranged from 5500 to $13000 \mathrm{~kJ} / \mathrm{d}(1310-3095 \mathrm{kcal} / \mathrm{d})$, however, $52 \%$ of the subjects underreported their energy intake. The chemical analysis of the composition of the diets was comparable to the calculated diets, except for the total fat and carbohydrate content of the walnut diet (Table 1). The analysed fat content was higher because the actual fat content of the walnuts was higher than indicated in the food composition tables (Table 2). All three experimental diets had a low to moderate glycaemic 
Table 3. Characteristics at baseline for all subjects

\begin{tabular}{|c|c|c|c|c|c|c|}
\hline \multirow[b]{2}{*}{ Variables } & \multicolumn{2}{|c|}{ Walnut diet $(n 21)$} & \multicolumn{2}{|c|}{ Cashew nut diet $(n 21)$} & \multicolumn{2}{|c|}{ Control diet $(n 22)$} \\
\hline & Mean & $95 \% \mathrm{Cl}$ & Mean & $95 \% \mathrm{Cl}$ & Mean & $95 \% \mathrm{Cl}$ \\
\hline Men/women & $10 / 11$ & - & $8 / 13$ & - & $11 / 11$ & - \\
\hline Age (years) & 45 & $40 \cdot 4,50 \cdot 2$ & 46 & $40 \cdot 7,50 \cdot 7$ & 45 & $40 \cdot 8,49 \cdot 3$ \\
\hline Weight (kg) & 107 & $99.4,115$ & 99 & $92 \cdot 5,106$ & 106 & $99 \cdot 2,113$ \\
\hline BMI $\left(\mathrm{kg} / \mathrm{m}^{2}\right)$ & $36 \cdot 0$ & $33 \cdot 3,38 \cdot 7$ & 34.4 & $32 \cdot 2,36 \cdot 6$ & $35 \cdot 1$ & $32 \cdot 8,37 \cdot 4$ \\
\hline WC (cm) & 109 & 103,115 & 105 & $98 \cdot 5,111$ & 108 & 102,113 \\
\hline Cigarette smokers & 1 & - & 0 & - & 3 & - \\
\hline
\end{tabular}

WC, waist circumference.

index and glycaemic load (Wolever \& Jenkins, 1985; FosterPowell et al. 2002; Table 1). The composition of walnuts (high in $\alpha$-linolenic acid and linoleic acid) and cashew nuts (high in oleic acid; Table 2) was reflected in the diets and resulted in the anticipated increase in PUFA and MUFA concentrations, in the diets respectively. In particular, the fatty acid composition of the walnut, cashew nut and control diets (expressed as $\%$ of total fatty acids) was $6.42 \% \alpha$-linolenic acid, $46.31 \%$ linoleic acid, $25.65 \%$ oleic acid; $1.05 \% \alpha$-linolenic acid, $27.82 \%$ linoleic acid, $43.65 \%$ oleic acid and $0.86 \% \alpha$-linolenic acid, $27.13 \%$ linoleic acid, $32.88 \%$ oleic acid, respectively.

\section{Lipid profiles}

In Table 4, the serum lipid concentrations displayed no significant changes between walnut, cashew nut and control groups at baseline and in response to the intervention. The subjects in the control diet group showed a small significant increase in HDL-C compared to baseline (Table 4). Results from both nut diets displayed no significant change in HDL-C, TAG, TC or LDL-C concentrations when compared to the baseline.

\section{Serum fructosamine and plasma glucose}

In Table 5, serum fructosamine and plasma glucose $(t=0 \mathrm{~min}$ and $t=120 \mathrm{~min}$ ) showed no significant difference at baseline between groups. Also, there was no significant difference in serum fructosamine between groups after the intervention diets. Plasma glucose concentrations $(t=0)$ increased significantly by $0.70 \mathrm{mmol} / \mathrm{l}(P=0.04)$ in the cashew nut group compared to the control group. Fructosamine significantly increased in the control diet group at the end of the study period, when compared to the baseline concentrations. The $2 \mathrm{~h}$ oral glucose tolerance test showed that there was no significant difference between the groups and when comparing baseline to end values.

\section{Blood pressure, uric acid and serum high-sensitivity C-reactive protein}

Of all three intervention diets, systolic and diastolic BP as well as uric acid concentrations displayed no significant change between groups at baseline and from baseline to end. The changes in S-hs CRP did not differ significantly between groups (Table 6). There was a significant increase in S-hs
CRP concentrations in the walnut intervention group from baseline to end and no significant change in the cashew nut and control groups when comparing baseline to end values. Although not statistically significant, S-hs CRP was also increased, approximately to the same extent, in the control and cashew nut groups. The increase in the walnut group is, therefore, probably not an independent effect of walnuts.

\section{Discussion}

As far as we know this well-designed parallel, randomized, controlled feeding trial investigating the effects of nuts on participants having the metabolic syndrome is the first study of its kind. Regarding our main objective, we found that both the walnut and the unsalted cashew nut intervention diets had no significant effect on the HDL-C, TAG, TC, LDL-C, serum fructosamine, S-hs CRP, BP and serum uric acid concentrations when compared to the control diet. Plasma glucose concentrations increased significantly in the cashew nut group compared to the control group.

In a recent systematic review (Mukuddem-Petersen et al. 2005), it was concluded from randomized controlled intervention trials that the consumption of 50-100 $\mathrm{g}$ (approximately 1.5-3.5 servings) of nuts five or more times/week as part of a heart healthy diet with a total fat content (high in MUFA and/or PUFA) of approximately $35 \% \mathrm{E}$ may significantly decrease TC and LDL-C. In lieu of the dynamic make-up of nuts, it deserves a mention that this decrease is not solely due to the changes in the fatty acid composition that results when nuts are included in the diet, but also as a result of the other components found in nuts.

Contrary to the outcomes of the present controlled feeding trial, four out of seven well-designed walnut studies (40$84 \mathrm{~g} / \mathrm{d}$ ) displayed a significant decrease in TC and LDL-C when compared to Step I (healthy; Sabate et al. 1993), Mediterranean (hypercholesterolaemic; Zambon et al. 2000; Ros et al. 2004) and Japanese (healthy; Iwamoto et al. 2002) diets. The average $\% \mathrm{E}$ from fat in the aforementioned nut diets and the control diets were 31 and $29 \%$, respectively. Two of the studies that showed no significant change in the lipid profile of hyperlipidaemic subjects who followed a walnut intervention diet $(64-78 \mathrm{~g} / \mathrm{d})$ when compared to a low-fat (30\%E from fat) and Step I diet (33\% E from fat) provided $\geq 38 \% \mathrm{E}$ from fat (Chisholm et al. 1998; Morgan et al. 2002), suggesting that the beneficial effects of nuts disappear with high fat intakes. Similarly, in the current study, the walnut diet $(60-100 \mathrm{~g} / \mathrm{d})$ was high in fat $(41 \% \mathrm{E}$ from fat) 
Table 4. Weight and serum lipids during interventions*

\begin{tabular}{|c|c|c|c|c|c|c|c|c|c|c|c|}
\hline & & \multicolumn{2}{|c|}{ Walnut diet (n 21) } & \multirow{2}{*}{$\begin{array}{l}P \text { value } \\
(\mathrm{B} v . \mathrm{E})\end{array}$} & \multicolumn{2}{|c|}{ Cashew nut diet ( $n$ 21) } & \multirow{2}{*}{$\begin{array}{l}P \text { value } \\
(\mathrm{B} v . \mathrm{E})\end{array}$} & \multicolumn{2}{|c|}{ Control diet (n 22) } & \multirow{2}{*}{$\begin{array}{l}P \text { value } \\
(\mathrm{B} v . \mathrm{E})\end{array}$} & \multirow{2}{*}{$\begin{array}{l}P \text { value between } \\
\text { groups (ANOVA) }\end{array}$} \\
\hline & & Mean & $95 \% \mathrm{Cl}$ & & Mean & $95 \% \mathrm{Cl}$ & & Mean & $95 \% \mathrm{Cl}$ & & \\
\hline \multirow[t]{3}{*}{ Weight (kg) } & $\mathrm{B}$ & 106 & $99 \cdot 4,115$ & \multirow[t]{3}{*}{0.50} & $99 \cdot 2$ & $92 \cdot 5,106$ & \multirow[t]{3}{*}{0.72} & 106 & $99 \cdot 2,113$ & \multirow[t]{3}{*}{0.14} & \multirow[t]{2}{*}{0.22} \\
\hline & $E$ & 106 & $99 \cdot 4,114$ & & 99.1 & $91 \cdot 9,106$ & & 105 & $98 \cdot 5,112$ & & \\
\hline & $\bar{\Delta}$ & -0.22 & $-0.87,0.44$ & & -0.17 & $-1.13,0.79$ & & -0.51 & $-1 \cdot 19,0.17$ & & 0.78 \\
\hline \multicolumn{12}{|l|}{$\begin{array}{l}\text { Serum lipids } \\
(\mathrm{mmol} / \mathrm{l})\end{array}$} \\
\hline \multirow[t]{3}{*}{ HDL-C } & $\mathrm{B}$ & 0.94 & $0.83,1.05$ & \multirow[t]{3}{*}{0.34} & 1.02 & $0.88,1 \cdot 16$ & \multirow[t]{3}{*}{0.71} & 0.85 & $0.77,0.93$ & \multirow[t]{3}{*}{0.04} & \multirow[t]{2}{*}{0.08} \\
\hline & $\mathrm{E}$ & 0.91 & $0.80,1.01$ & & 1.01 & $0.90,1.12$ & & 0.91 & $0.82,1.0$ & & \\
\hline & $\Delta$ & -0.03 & $-0.10,0.04$ & & -0.01 & $-0.09,0.06$ & & 0.06 & $0,0.11$ & & 0.11 \\
\hline \multirow[t]{4}{*}{ TAG } & $\mathrm{B}$ & 1.90 & $1.48,2 \cdot 32$ & \multirow[t]{3}{*}{0.79} & 1.81 & $1.33,2 \cdot 30$ & \multirow[t]{3}{*}{0.36} & 1.86 & $1 \cdot 55,2 \cdot 16$ & \multirow[t]{3}{*}{0.41} & 0.96 \\
\hline & $\mathrm{E}$ & 1.86 & $1 \cdot 44,2 \cdot 28$ & & 1.64 & $1.23,2.05$ & & 1.96 & $1.62,2.31$ & & \\
\hline & $\Delta$ & -0.04 & $-0.35,0.27$ & & -0.16 & $-0.52,0.20$ & & 0.11 & $-0.16,0.38$ & & 0.45 \\
\hline & & Median & $\begin{array}{c}25,75 \\
\text { Percentiles }\end{array}$ & $\begin{array}{l}P \text { value } \\
(B v . E)\end{array}$ & Median & $\begin{array}{c}25,75 \\
\text { Percentiles }\end{array}$ & $\begin{array}{l}P \text { value } \\
(B v . E)\end{array}$ & Median & $\begin{array}{c}25,75 \\
\text { Percentiles }\end{array}$ & $\begin{array}{l}P \text { value } \\
(B v . E)\end{array}$ & $\begin{array}{l}P \text { value between } \\
\text { groups (ANOVA) }\end{array}$ \\
\hline \multirow[t]{3}{*}{ TC } & B & 4.80 & $4.54,5 \cdot 18$ & \multirow[t]{3}{*}{0.83} & 4.49 & $3.98,5.34$ & \multirow[t]{3}{*}{0.62} & 4.90 & $4 \cdot 39,5 \cdot 52$ & \multirow[t]{3}{*}{0.09} & \multirow[t]{2}{*}{0.55} \\
\hline & $\mathrm{E}$ & 4.72 & $4.28,5.76$ & & 4.51 & $3.87,5.64$ & & $5 \cdot 39$ & $4.44,5.83$ & & \\
\hline & $\Delta$ & -0.03 & $-0.30,0.37$ & & 0.07 & $-0.22,0.49$ & & 0.07 & $-0.06,0.60$ & & 0.46 \\
\hline \multirow[t]{3}{*}{ LDL-C } & $B$ & 2.99 & $2.63,3.29$ & \multirow[t]{3}{*}{0.36} & 2.64 & $2 \cdot 33,3 \cdot 16$ & \multirow[t]{3}{*}{0.25} & $3 \cdot 21$ & $2.79,3.79$ & \multirow[t]{3}{*}{0.22} & 0.11 \\
\hline & $\mathrm{E}$ & $3 \cdot 19$ & $2.38,3.94$ & & $2 \cdot 84$ & $2.26,3.60$ & & 3.36 & $2 \cdot 86,3.84$ & & \\
\hline & $\Delta$ & 0.18 & $-0.21,0.50$ & & 0.12 & $-0.25,0.55$ & & 0.19 & $-0.11,0.46$ & & 1.00 \\
\hline
\end{tabular}
B, baseline (after 3-week run-in period); B v. E, $P$ values for change from baseline to end of intervention period; E, end; HDL-C, HDL cholesterol; LDL-C, LDL cholesterol; TC, total cholesterol; $\Delta$, change from baseline to end.
* Significance was set at $P \leq 0.05$. 
Table 5. Serum fructosamine and plasma glucose during interventions

\begin{tabular}{|c|c|c|c|c|c|c|c|c|c|c|c|}
\hline \multirow[b]{2}{*}{ Markers } & & \multicolumn{2}{|c|}{ Walnut diet } & \multirow{2}{*}{$\begin{array}{l}P \text { value } \\
(B v . E)\end{array}$} & \multicolumn{2}{|c|}{ Cashew nut diet } & \multirow{2}{*}{$\begin{array}{l}P \text { value } \\
(\mathrm{B} v . \mathrm{E})\end{array}$} & \multicolumn{2}{|c|}{ Control diet } & \multirow{2}{*}{$\begin{array}{l}P \text { value } \\
(B \quad v . E)\end{array}$} & \multirow{2}{*}{$\begin{array}{l}P \text { value between } \\
\text { groups (ANOVA) }\end{array}$} \\
\hline & & Mean & $95 \% \mathrm{Cl}$ & & Mean & $95 \% \mathrm{Cl}$ & & Mean & $95 \% \mathrm{Cl}$ & & \\
\hline \multirow{4}{*}{$\begin{array}{l}\text { Serum fructosamine } \\
\quad(\mu \mathrm{mol} / \mathrm{l})\end{array}$} & $\mathrm{B}$ & 210 & 202,218 & 0.79 & 212 & 206,218 & 0.32 & 204 & 198,210 & 0.04 & 0.23 \\
\hline & $\mathrm{E}$ & 209 & 201,217 & & 214 & 206,222 & & 210 & 203,218 & & \\
\hline & $\Delta$ & -0.95 & $-8 \cdot 16,6 \cdot 26$ & & $2 \cdot 29$ & $-2 \cdot 38,6 \cdot 96$ & & 6.00 & $0.20,11.8$ & & 0.24 \\
\hline & & Median & $\begin{array}{c}25,75 \\
\text { Percentiles }\end{array}$ & $\begin{array}{l}P \text { value } \\
(\mathrm{B} v . \mathrm{E})\end{array}$ & Median & $\begin{array}{c}25,75 \\
\text { Percentiles }\end{array}$ & $\begin{array}{l}P \text { value } \\
\text { (B v. E) }\end{array}$ & Median & $\begin{array}{c}25,75 \\
\text { Percentiles }\end{array}$ & $\begin{array}{l}P \text { value } \\
(\mathrm{B} v . \mathrm{E})\end{array}$ & $\begin{array}{l}P \text { value between } \\
\text { groups (ANOVA) }\end{array}$ \\
\hline \multirow{3}{*}{$\begin{array}{l}\text { Plasma glucose } t=0 \\
\qquad(\mathrm{mmol} / \mathrm{l})\end{array}$} & B & $4 \cdot 50$ & $4 \cdot 30,5 \cdot 20$ & 0.64 & 4.70 & $4 \cdot 30,5 \cdot 10$ & 0.03 & 4.55 & $4 \cdot 30,5 \cdot 40$ & $0 \cdot 18$ & 0.73 \\
\hline & $\mathrm{E}$ & $4 \cdot 70$ & $4.00,5.40$ & & $5 \cdot 30$ & $4 \cdot 70,6 \cdot 20$ & & 4.55 & $3.80,5.40$ & & \\
\hline & $\Delta$ & 0.40 & $-0.60,0.70$ & & $0 \cdot 70^{\star}$ & $-0.30,1 \cdot 60$ & & -0.75 & $-1.40,0.80$ & & 0.04 \\
\hline \multirow{3}{*}{$\begin{array}{l}\text { Plasma glucose. } t=120 \\
\quad(\mathrm{mmol} / \mathrm{l})\end{array}$} & B & $4 \cdot 70$ & $4 \cdot 50,5 \cdot 40$ & 0.09 & $4 \cdot 60$ & $4 \cdot 10,5 \cdot 30$ & 0.25 & $4 \cdot 60$ & $4 \cdot 30,5 \cdot 10$ & $0 \cdot 87$ & 0.94 \\
\hline & $E$ & $5 \cdot 50$ & $4 \cdot 40,6 \cdot 30$ & & $5 \cdot 00$ & $4 \cdot 20,5 \cdot 90$ & & 4.80 & $3 \cdot 90,6 \cdot 10$ & & \\
\hline & $\Delta$ & 0.50 & $-0.20,1 \cdot 30$ & & 0.40 & $0.70,1.40$ & & -0.20 & $-0.90,1 \cdot 10$ & & 0.80 \\
\hline
\end{tabular}

B, baseline (after 3-week run-in period); B v. E, $P$ values for change from baseline to end of intervention period; $E$, end; $\Delta$, change from baseline to end.

Median value was significantly different from that of the control group: ${ }^{*} P \leq 0.05$

Table 6. Blood pressure, uric acid and C-reactive protein changes within and between groups during intervention*

\begin{tabular}{|c|c|c|c|c|c|c|c|c|c|c|c|}
\hline \multirow[b]{2}{*}{ Markers } & & \multicolumn{2}{|c|}{ Walnut diet } & \multirow{2}{*}{$\begin{array}{l}P \text { value } \\
(B \text { v. E) }\end{array}$} & \multicolumn{2}{|c|}{ Cashew nut diet } & \multirow{2}{*}{$\begin{array}{l}P \text { value } \\
(\mathrm{B} v . \mathrm{E})\end{array}$} & \multicolumn{2}{|c|}{ Control diet } & \multirow{2}{*}{$\begin{array}{l}P \text { value } \\
(B \text { v. E) }\end{array}$} & \multirow{2}{*}{$\begin{array}{l}P \text { value between } \\
\text { groups (ANOVA) }\end{array}$} \\
\hline & & Mean & $95 \% \mathrm{Cl}$ & & Mean & $95 \% \mathrm{Cl}$ & & Mean & $95 \% \mathrm{Cl}$ & & \\
\hline \multicolumn{12}{|l|}{$\mathrm{BP}(\mathrm{mmHg})$} \\
\hline \multirow[t]{3}{*}{ Systolic } & B & 128 & 126,131 & 0.26 & 131 & 126,135 & 0.28 & 131 & 125,137 & 0.40 & 0.66 \\
\hline & $E$ & 130 & 126,133 & & 128 & 123,134 & & 133 & 128,137 & & \\
\hline & $\Delta$ & $2 \cdot 21$ & $-1 \cdot 74,6 \cdot 16$ & & -2.45 & $-7.09,2.19$ & & 1.74 & $-2.45,5.92$ & & 0.22 \\
\hline \multirow[t]{3}{*}{ Diastolic } & B & $78 \cdot 7$ & $76 \cdot 3,81 \cdot 0$ & 0.49 & $77 \cdot 0$ & $74 \cdot 0,80 \cdot 0$ & 0.72 & $79 \cdot 2$ & $76 \cdot 1,82 \cdot 2$ & 0.79 & 0.50 \\
\hline & $\mathrm{E}$ & $79 \cdot 1$ & $75 \cdot 9,82 \cdot 0$ & & $76 \cdot 0$ & $73 \cdot 1,80 \cdot 0$ & & $79 \cdot 6$ & $76 \cdot 9,82 \cdot 4$ & & \\
\hline & $\Delta$ & $1 \cdot 21$ & $-2 \cdot 39,4 \cdot 81$ & & -0.59 & $-4.01,2.83$ & & 0.48 & $-3.11,4.07$ & & 0.76 \\
\hline \multirow{4}{*}{$\begin{array}{l}\text { Serum uric } \\
\quad \text { acid }(\mu \mathrm{mol} / \mathrm{l})\end{array}$} & $\mathrm{B}$ & 388 & 347,429 & 0.30 & 373 & 329,418 & 0.65 & 412 & 368,456 & 0.57 & 0.42 \\
\hline & $\mathrm{E}$ & 401 & 361,440 & & 377 & 328,426 & & 416 & 376,457 & & \\
\hline & $\Delta$ & $12 \cdot 6$ & $-12 \cdot 2,37 \cdot 3$ & & 3.86 & $-13 \cdot 5,21 \cdot 2$ & & 4.64 & $-12 \cdot 1,21 \cdot 4$ & & 0.78 \\
\hline & & Median & $\begin{array}{c}25,75 \\
\text { Percentiles }\end{array}$ & $\begin{array}{l}P \text { value } \\
(\mathrm{B} v . \mathrm{E})\end{array}$ & Median & $\begin{array}{c}25,75 \\
\text { Percentiles }\end{array}$ & $\begin{array}{l}P \text { value } \\
(B v . E)\end{array}$ & Median & $\begin{array}{c}25,75 \\
\text { Percentiles }\end{array}$ & $\begin{array}{l}P \text { value } \\
(B \text { v. E) }\end{array}$ & $\begin{array}{l}P \text { value between } \\
\text { groups (ANOVA) }\end{array}$ \\
\hline \multirow[t]{3}{*}{ S-hs CRP (mg/l) } & $\mathrm{B}$ & $2 \cdot 40$ & $0.60,4.80$ & 0.01 & $4 \cdot 30$ & $1 \cdot 80,5 \cdot 50$ & 0.07 & 3.05 & $1 \cdot 30,6 \cdot 10$ & 0.21 & 0.17 \\
\hline & $\mathrm{E}$ & 3.00 & $1 \cdot 10,5 \cdot 50$ & & $4 \cdot 20$ & $2 \cdot 10,6 \cdot 40$ & & $3 \cdot 65$ & $2 \cdot 20,7 \cdot 30$ & & \\
\hline & $\Delta$ & 0.50 & $0.10,1.50$ & & 0.20 & $-0.50,3.20$ & & 0.65 & $-0.30,2 \cdot 20$ & & 0.38 \\
\hline
\end{tabular}

B, baseline; B v. E, $P$ values for change from baseline to end of intervention period; BP, blood pressure; E, end; S-hs CRP, serum high-sensitivity C-reactive protein; $\Delta$, change from baseline to end.

${ }^{*}$ Significance was set at $P \leq 0.05$. 
compared to the control diet (33\% $\mathrm{E}$ from fat). However, highPUFA diets, similar to the walnut diet in the current study, are predicted to reduce TC and LDL-C concentrations (Mensink $\&$ Katan, 1992). Based on the predictive equations of Mensink \& Katan (1992), which predict changes in TC and LDL-C concentrations according to changes in the fatty acid content of the diet, the walnut diet should have reduced the TC and LDL-C concentrations with 0.34 and $0.30 \mathrm{mmol} / 1$, respectively, compared to the control diet. The lack of effect can possibly be ascribed to the low TC and LDL-C concentrations of the subjects at baseline, as these low concentrations make it difficult to show a further benefit.

Most of the walnut studies to date did not show an effect on HDL-C and TAG concentrations (Mukuddem-Petersen et al. 2005). Sabate et al. (1993) showed a decrease in HDL-C that could possibly have been due to the high PUFA content on the walnut diet $(17 \% \mathrm{E})$ compared to the control diet $(10 \% \mathrm{E})$. High intakes of PUFA $(>10 \% \mathrm{E})$ may decrease HDL-C (Riccardi et al. 2003). Although the PUFA content of the walnut diet in the current study was also much higher compared to the control diet $(21.4$ v. $9.5 \% \mathrm{E})$, the HDL-C did not differ between the diets.

As no clinical trials have been done on cashew nuts before, we considered almond studies as they are similar in composition to cashew nuts. We expected the cashew nut study to have a beneficial effect on TC and LDL-C concentrations as seen in previous almond nut studies. In this context three out of four well-designed almond studies $(54-100 \mathrm{~g} / \mathrm{d}) \mathrm{ran}-$ ging from 32 to $39 \% \mathrm{E}$ from fat, significantly decreased $\mathrm{TC}$ and LDL-C in hypercholesterolaemic (Spiller et al. 1998; Jenkins et al. 2002) and normocholesterolaemic (Sabate et al. 2003) subjects compared to subjects on a control diet (35\% from fat), low-fat (26.3\%E from fat) and Step I diet (30\%E from fat) (Sabate et al. 2003). In the present study, the cashew nut $(66-115 \mathrm{~g} / \mathrm{d})$ diet $(37 \% \mathrm{E}$ from fat) had no significant beneficial effect on the lipid profile (Table 4) when compared to the control diet that is lower in fat $33 \% \mathrm{E}$ from fat). This outcome was very similar to results found by Lovejoy et al. (2002) who showed that 57-113 g almonds/d (39\% $\mathrm{E}$ from fat) had no significant beneficial effect on the lipid profile of diabetic subjects when compared to a highfat $(37 \% \mathrm{E}$ from fat) control group. The same outcome was achieved when the same amount of almonds $(27 \% \mathrm{E})$ as part of a low-fat diet was compared to a low-fat $(26 \% \mathrm{E}$ from fat) control diet (Lovejoy et al. 2002). Based on differences in fatty acid content of the cashew nut and control diets in the current study the predicted reductions in TC and LDL-C concentrations with the cashew nut diet were very small $(-0.14 \mathrm{mmol} / \mathrm{l}$ for both TC and LDL-C). However, it has been shown that nuts may reduce TC and LDL-C concentrations beyond the effects predicted based solely on fatty acid profiles (Mukuddem-Petersen et al. 2005). As mentioned earlier, the low TC and LDL-C concentrations at baseline might explain the lack of effects. Other possible reasons for the non-significance in lipid concentrations need to be explored.

No direct studies have been done to investigate the effects of nuts on BP. Despite this, we anticipated an improvement in the BP readings with the walnut and cashew nut diets based on their fatty acid composition. In particular, emerging research has suggested possible health benefits associated with modest increases in dietary $\alpha$-linolenic acid (walnuts), including reduced BP (Ferrara et al. 2000; Hermansen, 2000; Hunter, 1990). Also, numerous studies conducted in healthy and hypertensive individuals have shown a beneficial effect of MUFA (cashew nuts) on a number of outcomes related to cardiovascular risk, including $\mathrm{BP}$ (Roche et al. 1998). However, no improvement in BP readings was seen after the nut intervention diets in the current controlled feeding trial.

Zhao et al. (2004) concluded that a diet high in $\alpha$-linolenic acid, obtained from walnuts, walnut oil and flaxseed oil, elicited cardioprotective effects and vascular anti-inflammatory effects. Regarding the latter, it has been reported that walnuts are amongst the dietary plants that contain the most antioxidants (Halvorsen et al. 2002) and several health effects have been ascribed to flavonoids (antioxidants) including reduced inflammation (Nijveldt et al. 2001). In the present study, the walnut diet (high in $\alpha$-linolenic acid) resulted in an increase in S-hs CRP concentrations, although this was probably not an independent effect of walnuts. Recently, some evidence has been presented for a beneficial effect of MUFA on a number of outcomes related to cardiovascular risk, including reduced inflammation (Ferrara et al. 2000). Consequently, a cashew nut diet (high in MUFA) could be expected to improve the inflammatory parameter CRP. However, this was not evident in the present study.

Numerous studies compared a low-fat diet $(21 \% ; 23 \%$; $29 \% \mathrm{E}$ from fat; Luscombe et al. 1999; Thomsen et al. 1999; Rodriguez-Villar et al. 2000; Perez-Jimenez et al. $2001)$ to a high-MUFA diet $(35 \% ; 40 \% \mathrm{E}$ from fat; Luscombe et al. 1999). The results of these studies provided similar glycaemic control. Those authors concluded that provided the intake of SFA is low, a MUFA diet with a total fat content of up to $40 \% \mathrm{E}$ has effects on glycaemic control that are similar to those of the traditional high-carbohydrate diet with fat limited to $25-30 \% \mathrm{E}$. An almond nut study conducted by Lovejoy et al. (2002) showed no effect on plasma glucose concentrations compared to a low-fat ( $26 \% \mathrm{E}$ from fat) control group (olive and rapeseed oil) in diabetics. In contrast to these previous findings, the significant increase of the plasma blood glucose $(t=0)$ seen in the cashew nut diet (high MUFA; $36.5 \% \mathrm{E}$ from fat) group was unexpected. Even though serum fructosamine is a short-term marker of glycaemic control, its concentrations remained unchanged in the cashew nut group compared to the control group that increased. It could be speculated that the aforementioned increase in serum fructosamine concentrations in the control group may be due to this group having lower baseline values compared to the other two groups.

ATP III recommends that obesity should be the primary target of intervention for the metabolic syndrome. In turn, the first line of therapy should be weight reduction reinforced with increased physical activity. A notion related to this is evident in the study by Esposito et al. (2004) where they displayed how a Mediterranean diet (high in MUFA and PUFA) that included nuts, weight loss and increased physical activity resulted in a significant reduction in S-hs CRP amongst other beneficial anti-inflammatory responses.

In conclusion, individuals having the metabolic syndrome showed no improvement in the markers of this syndrome after following a walnut diet or a cashew nut diet ( 8 weeks) 
compared to a control diet while maintaining body weight. Most of the study population was obese (average BMI 35) and sedentary therefore it could be speculated that with such a high degree of obesity that even a 'good diet including nuts' would not suffice in inducing beneficial effects without weight loss. Firstly, it may be suggested that maintenance of body weight may have masked the positive metabolic effects of the nut diets. Especially, if these diets mediate its beneficial effects mainly through central appetite suppression and consequent body weight reduction. Wien et al. (2003) showed how a low-energy nut diet resulted in sustained weight reduction and improved the preponderance of abnormalities associated with the metabolic syndrome. Future nut research on these aspects are worthy of exploration.

\section{Acknowledgements}

A sincere word of thanks to M. C. Lessing, E. Pienaar, Z. White, A. Greyling, C. de Witt, J. Wheeler, J. Bekker, C. Jansen van Rensburg, M. Bailey, L. Loots, V. van Scheltinga, L. Wiggett, L. Davies, L. van Wyk, E. Snyman, F. Mpho and T. Holele, A. Schutte, H. Huisman, J. van Rooyen, S. Jordaan, F. van der Westhuizen, C. S. Venter, H. H. Wright, H. S. Kruger, H. van't Riet, R. Breet, A. Van Graan, M. van Lieshout, D. Loots, M. Pieters-Loots, K. Moruisi, M. Opperman and M. Phometsi for contributing in various ways to the successful execution and completion of the controlled feeding trial - The Nut Study. Financial support was received from The National Research Foundation (NRF) and the South African governments' Technology and Human Resources for Industry Program (THRIP). Various food donations for the controlled feeding trial were received from the following food companies: Tiger Brands, Pick 'n Pay, Clover and Unilever. We declare that we have no conflict of interest.

\section{References}

American Association of Clinical Chemistry (2003) Abstracts of the 55th Annual Meeting of the AACC, Philadelphia, Pennsylvania, USA, July 20-24. Clin Chem 20 (49), A2-A182.

AOAC International (2002) Official Methods of Analysis of AOAC International. Gaithersburg, MD: AOAC International.

Bingham SA (1991) Limitations of the various methods for collecting dietary intake data. Ann Nutr Metab 35, 117-127.

Briefel RR, Sempos CT, McDowell MA, Chien S \& Alaimo K (1997) Dietary methods research in the third National Health and Nutrition Examination Survey: underreporting of energy intake. Am J Clin Nutr 65, 1203S-1209S.

Chisholm A, Mann J, Skeaff M, Frampton C, Sutherland W, Duncan A \& Tiszavari S (1998) A diet rich in walnuts favourably influences plasma fatty acid profile in moderately hyperlipidaemic subjects. Eur J Clin Nutr 52, 12-16.

Dansinger ML \& Schaefer EJ (2006) Low-carbohydrate or low-fat diets for the metabolic syndrome? Curr Diabet Rep 6, 55-63.

Dreher ML, Maher CV \& Kearney P (1996) The traditional and emerging role of nuts in healthful diets. Nutr Rev 54, 241-245.

Esposito K, Marfella R, Ciotola M, et al. (2004) Effect of a mediterranean-style diet on endothelial dysfunction and markers of vascular inflammation in the metabolic syndrome: a randomized trial. JAMA 292, 1440-1446.

Ferrara LA, Raimondi AS, D'Episcopo L, Guida L, Dello RA \& Marotta T (2000) Olive oil and reduced need for antihypertensive medications. Arch Intern Med 160, 837-842.
Ford ES (2004) Prevalence of the metabolic syndrome in US populations. Endocrinol Metab Clin N Am 33, 333-350.

Ford ES, Giles WH \& Dietz WH (2002) Prevalence of the metabolic syndrome among US adults: findings from the third National Health and Nutrition Examination Survey. JAMA 287, 356-359.

Foster-Powell K, Holt SH \& Brand-Miller JC (2002) International table of glycemic index and glycemic load values: 2002. Am J Clin Nutr 76, 5-56.

Freire RD, Cardoso MA, Gimeno SGA \& Ferreira SRG (2005) Dietary fat is associated with metabolic syndrome in Japanese Brazilians. Diabetes Care 28, 1779-1785.

Fujioka K, Greenway F, Sheard J \& Ying Y (2006) The effects of grapefruit on weight and insulin resistance: relationship to the metabolic syndrome. J Med Food 9, 49-54.

Giacco R, Parillo M, Rivellese AA, et al. (2000) Long-term dietary treatment with increased amounts of fiber-rich low-glycemic index natural foods improves blood glucose control and reduces the number of hypoglycemic events in type 1 diabetic patients. Diabetes Care 23, 1461-1466.

Halvorsen BL, Holte K, Myhrstad MC, et al. (2002) A systematic screening of total antioxidants in dietary plants. J Nutr 132, 461-471.

He K, Liu K, Daviglus ML, Morris SJ, Loria CM, Van Horn L, Jacobs DR Jr \& Savage PJ (2006) Magnesium intake and incidence of metabolic syndrome among young adults. Circulation 113, $1675-1682$.

Hermansen K (2000) Diet, blood pressure and hypertension. Br J Nutr 83 (Suppl. 1), S113-S119.

Hunter JE (1990) n-3 fatty acids from vegetable oils. Am J Clin Nutr 51, 809-814.

Iwamoto M, Imaizumi K, Sato M, et al. (2002) Serum lipid profiles in Japanese women and men during consumption of walnuts. Eur $J$ Clin Nutr 56, 629-637.

Jenkins DJ, Kendall CW, Marchie A, et al. (2002) Dose response of almonds on coronary heart disease risk factors: blood lipids, oxidized low-density lipoproteins, lipoprotein(a), homocysteine, and pulmonary nitric oxide: a randomized, controlled, crossover trial. Circulation 106, 1327-1332.

Jimenez-Cruz A, Seimandi-Mora H \& Bacardi-Gascon M (2003) Effect of low glycemic index diets in hyperlipidemia. Nutr Hosp 18, 331-335.

Kruger HS, Venter CS \& Steyn HS (2004) A standardized physical activity questionnaire for a population in transition: the Thusa study. Afr J Phys Health Educ Recreation Dance 6, 54-64.

Kruger M, Langenhoven M \& Faber M(1992) Fatty Acid and Amino Acid Composition Tables. Supplement to MRC Food Composition Tables (1991). Tygerberg: Medical Research Council of South Africa.

Langenhoven M, Kruger M, Gouws E \& Faber M (1991) MRC Food Composition Tables. Supplement, 3rd ed., Tygerberg: Medical Research Council of South Africa.

Lovejoy JC, Most MM, Lefevre M, Greenway FL \& Rood JC (2002) Effect of diets enriched in almonds on insulin action and serum lipids in adults with normal glucose tolerance or type 2 diabetes. Am J Clin Nutr 76, 1000-1006.

Luscombe ND, Noakes M \& Clifton PM (1999) Diets high and low in glycemic index versus high monounsaturated fat diets: effects on glucose and lipid metabolism in NIDDM. Eur J Clin Nutr 53, 473-478.

McKeown NM, Meigs JB, Liu S, Saltzman E, Wilson PW \& Jacques PF (2004) Carbohydrate nutrition, insulin resistance, and the prevalence of the metabolic syndrome in the Framingham Offspring Cohort. Diabetes Care 27, 538-546.

Mensink RP \& Katan MB (1992) Effect of dietary fatty acids on serum lipids and lipoproteins. A meta-analysis of 27 trials. Arterioscler Thromb 12, 911-919.

Michalsen A, Lehmann N, Pithan C, Knoblauch NTM, Moebus S, Kannenberg F, Binder L, Budde T \& Dobos GJ (2006) Mediterranean diet has no effect on markers of inflammation and metabolic 
risk factors in patients with coronary artery disease. Eur $J$ Clin Nutr 60, 478-485.

Morgan JM, Horton K, Reese D, Carey C, Walker K \& Capuzzi DM (2002) Effects of walnut consumption as part of a low-fat, lowcholesterol diet on serum cardiovascular risk factors. Int $J$ Vitam Nutr Res 72, 341-347.

Moruisi KG, Oosthuizen W \& Opperman AM (2006) Phytosterols/ stanols lower cholesterol concentrations in familial hypercholesterolemic subjects: a systematic review with meta-analysis. J Am Coll Nutr 25, 41-48.

Mukuddem-Petersen J, Oosthuizen W \& Jerling JCJ (2005) A systematic review of the effects of nuts on blood lipid profiles in humans. J Nutr 135, 2082-2089.

Muzio F, Mondazzi L, Sommariva D \& Brachi A (2005) Long-term effects of low-calorie diet on the metabolic syndrome in obese nondiabetic patients. Diabetes Care 28, 1485-1486.

National Cholesterol Education Program (2001) Executive summary of the third report of the National Cholesterol Education Program (NCEP) Expert Panel on Detection, Evaluation, and Treatment of High Blood Cholesterol in Adults (Adult Treatment Panel III). JAMA 285, 2486-2497.

Nijveldt RJ, van Nood E, van Hoorn DE, Boelens PG, van Norren K \& van Leeuwen PA (2001) Flavonoids: a review of probable mechanisms of action and potential applications. Am J Clin Nutr 74, $418-425$

Oosthuizen W, Vorster HH, Kruger A, Venter CS, Kruger HS \& de Ridder JH (2002) Impact of urbanisation on serum lipid profiles - the THUSA survey. S Afr Med J 92, 723-728.

Perez-Jimenez F, Lopez-Miranda J, Pinillos MD, Gomez P, Paz-Rojas E, Montilla P, Marin C, Velasco MJ, Blanco-Molina A, Jimenez Pereperez JA \& Ordovas JM (2001) A Mediterranean and a highcarbohydrate diet improve glucose metabolism in healthy young persons. Diabetologia 44, 2038-2043.

Pieters M, Oosthuizen W, Jerling JC, Loots DT, Mukuddem-Petersen J \& Hanekom SM (2005) Clustering of haemostatic variables and the effect of high cashew and walnut diets on these variables in metabolic syndrome patients. Blood Coag Fibrin 16, 429-437.

Riccardi G, Giacco R \& Rivellese AA (2004) Dietary fat, insulin sensitivity and the metabolic syndrome. Clin Nutr 23, 447-456.

Riccardi G, Rivellese AA \& Williams CM (2003) The cardiovascular system. In Nutrition and Metabolism, pp. 224-246 [MJ Gibney, IA Macdonald and HM Roche, editors]. Oxford: Blackwell Science.

Roche HM, Zampelas A, Knapper JM, et al. (1998) Effect of longterm olive oil dietary intervention on postprandial triacylglycerol and factor VII metabolism. Am J Clin Nutr 68, 552-560.

Rodriguez-Villar C, Manzanares JM, Casals E, Perez-Heras A, Zambon D, Gomis R \& Ros E (2000) High-monounsaturated fat, olive oil-rich diet has effects similar to a high-carbohydrate diet on fasting and postprandial state and metabolic profiles of patients with type 2 diabetes. Metabolism 49, 1511-1517.
Ros E, Nunez I, Perez-Heras A, et al. (2004) A walnut diet improves endothelial function in hypercholesterolemic subjects: a randomized crossover trial. Circulation 109, 1609-1614.

Sabate J (1993) Does nut consumption protect against ischaemic heart disease? Eur J Clin Nutr 47, Suppl. 1, S71-S75.

Sabate J, Fraser GE, Burke K, Knutsen SF, Bennett H \& Lindsted KD (1993) Effects of walnuts on serum lipid levels and blood pressure in normal men. $N$ Engl J Med 328, 603-607.

Sabate J, Haddad E, Tanzman JS, Jambazian P \& Rajaram S (2003) Serum lipid response to the graduated enrichment of a Step I diet with almonds: a randomized feeding trial. Am J Clin Nutr 77, $1379-1384$.

Shirai K (2004) Obesity as the core of the metabolic syndrome and the management of coronary heart disease. Curr Med Res Opin 20, 295-304.

Spiller GA, Jenkins DA, Bosello O, Gates JE, Cragen LN \& Bruce B (1998) Nuts and plasma lipids: an almond-based diet lowers LDLC while preserving HDL-C. J Am Coll Nutr 17, 285-290.

Thomsen C, Rasmussen O, Christiansen C, Pedersen E, Vesterlund M, Storm H, Ingerslev J \& Hermansen K (1999) Comparison of the effects of a monounsaturated fat diet and a high carbohydrate diet on cardiovascular risk factors in first degree relatives to type-2 diabetic subjects. Eur J Clin Nutr 53, 818-823.

Tapsell LC, Gillen LJ, Patch CS, Batterham M, Owen A, Bare M \& Kennedy M (2004) Including walnuts in a low-fat/modified-fat diet improves HDL cholesterol-to-total cholesterol ratios in patients with type 2 diabetes. Diabetes Care 27, 2777-2783.

van Jaarsveld PJ, Smuts CM, Tichelaar HY, Kruger M \& Benade AJ (2000) Effect of palm oil on plasma lipoprotein concentrations and plasma low-density lipoprotein composition in non-human primates. Int J Food Sci Nutr 51, Suppl., S21-S30.

Wien MA, Sabate JM, Ikle' DN, Cole SE \& Kandeel FR (2003) Almonds vs complex carbohydrates in a weight reduction program. Int J Obes 27, 1365-1372.

Wirfalt E, Hedblad B, Gullberg B, et al. (2001) Food patterns and components of the metabolic syndrome in men and women: a cross-sectional study within the Malmo Diet and Cancer cohort. Am J Epidemiol 154, 1150-1159.

Wolever TM \& Jenkins DJ (1985) Application of glycaemic index to mixed meals. Lancet 2, 944.

Zambon D, Sabate J, Munoz S, et al. (2000) Substituting walnuts for monounsaturated fat improves the serum lipid profile of hypercholesterolemic men and women. A randomized crossover trial. Ann Intern Med 132, 538-546.

Zhao G, Etherton TD, Martin KR, West SG, Gillies PJ \& Kris-Etherton PM (2004) Dietary $\alpha$-linolenic acid reduces inflammatory and lipid cardiovascular risk factors in hypercholesterolemic men and women. J Nutr 134, 2991-2997.

Zibaeenezhad MJ, Shamsnia SJ \& Khorasani M (2005) Walnut consumption in hyperlipidemic patients. Angio 56, 581-583. 